\title{
MRS Elects Officers, Councillors for 1998
}

Members of the Materials Research Society have elected two officers and six councillors to join the 1998 Council, which consists of the executive committee and 15 councillors. The annual election ended October 10, 1997.

\section{MRS Officers}

President

Robert J. Nemanich (1998)

North Carolina State University

Immediate Past President

Robert Hull (1998)

University of Virginia

Vice President (President-Elect)

*Ronald Gibala (1998)

University of Michigan

Secretary: *Chuang Chuang Tsai (1999)

Applied Komatsu Technology

Treasurer: Alan J. Hurd (1998)

Sandia National Laboratories
1998 MRS Councillors

Cammy R. Abernathy (1998)

University of Florida

Harry A. Atwater (1998)

California Institute of Technology

*Michael J. Aziz (2000)

Harvard University

*Katayun Barmak (2000)

Lehigh University

Theodore M. Besmann (1999)

Oak Ridge National Laboratory

*David J. Eaglesham (2000)

Bell Laboratories, Lucent Technologies

Martin L. Green (1998)

Bell Laboratories, Lucent Technologies

*Alexander H. King (2000)

State University of NY at Stony Brook
*Karen Maex (2000)

IMEC, Belgium

Amy J. Moll (1999)

Hewlett Packard

Virginia M. Oversby (1998)

VMO Konsult

Tim Sands (1999)

University of California-Berkeley

Lyle H. Schwartz (1998)

Associated Universities, Inc.

*Alan I. Taub (2000)

Ford Motor Company

James S. Williams (1998)

Australian National University

(Terms of office expire at the end of the years indicated in parentheses.)

${ }^{*}$ Newly elected.

\section{Graduate Student Award Finalists Compete at 1997 MRS Fall Meeting}

Twenty-six finalists will compete for the MRS Graduate Student Awards to be presented during the awards ceremony on Wednesday, December 3, at 6:00 p.m., in the Boston Marriott Hotel, Salon E at the 1997 MRS Fall Meeting. The Graduate Student Award Special Talk Session, in which each finalist gives a 10-minute presentation, will be held on Monday, December 1, at noon.

Following is the list of finalists, their places of study, titles of papers, and the symposium or symposia in which each finalist is participating:

Kathleen M. Amm, Florida State University, "Processing and Properties of $(\mathrm{Hg}, \mathrm{Bi}) \mathrm{Ba}_{2} \mathrm{Ca}_{2} \mathrm{Cu}_{3} \mathrm{O}_{4}$ Tapes" and "Synthesis and Processing of Bi-Doped $\mathrm{Hg}$-1223 Superconductor" (Symposium T)

Martin Z. Bazant, Harvard University, "Environment-Dependent Interatomic Potential for Bulk Silicon" (Symposium R)

J. D. Brown, North Carolina State University, "The First Nitride Laser Diode on Silicon Carbide" (Symposium D)

Lila J. Chamberlain, Massachusetts Institute of Technology, "Cellular Reaction to Synthetic and Natural Polymeric Tube Implants Used for Peripheral Nerve Regeneration" (Symposium O)

Danielle R. Chamberlin, University of CaliforniaBerkeley, "Multivalent Acceptor Doped Germanium Lasers: A Solid-State Tunable Source From 75 to $300 \mu \mathrm{m}^{\prime \prime}$ (Symposium F)

Jinghong Chen, University of Southern California, "High E-O Coefficient Polymers Based on a Chromophore Containing Isophorone Moiety for Second-Order Nonlinear Optics" (Symposium J)

Anthony D. Dinsmore, University of Pennsylvania, "Hard Spheres Inside Vesicles: Depletion Forces and Membrane Curvature" (Symposium L)

Stephen A. Empedocles, Massachusetts Institute of Technology, "Photoluminescence Spectroscopy of Single CdSe Nanocrystallite Quantum Dots"

\section{(Symposium C)}

Michael Fasolka, Massachusetts Institute of Technology, "Observed Substrate TopographyMediated Lateral Patterning of Diblock Copolymer Films" (Symposium N)

Jennifer A. Hollingsworth, Washington University, "Spray Chemical Vapor Deposition of CuInS $_{2}$ Thin Films: The Influence of Deposition Conditions on Film Quality" and "LowTemperature, Solution-Based Route to NanoIndium Sulfide Phases and a New Chemical-Bath Process for Deposition of Orthorhombic InS Thin Films" (Symposium W)

C. Esther Jesurum, Massachusetts Institute of Technology, "Modeling Collision Cascade Structure of $\mathrm{SiO}_{2}, \mathrm{Si}_{3} \mathrm{~N}_{4}$, and $\mathrm{SiC}$ Using Local Topological Approaches" (Symposium KK)

Bijaya B. Karki, University of Edinburgh, "High Pressure Elasticity of the Major Silicate and Oxide Minerals of the Earth's Lower Mantle" (Symposium DD)

Ilya Koltover, University of California-Santa Barbara, "Structure and Interactions in SelfAssembled DNA-Cationic Lipid Complexes in the Presence of Single and Multivalent Counterions" and "Melting and Interactions in Multilayers of Two-Dimensional Crystals of Membrane-Protein Bacteriorhodopsin" (Symposia $\mathrm{K}$ and $\mathrm{L}$ )

Francois Leonard, University of Toronto, "Alloy Decomposition and Surface Instabilities in Thin Films" and "Phase Separation in Heteroepitaxial Thin Film Growth" (Symposium A)

Alexander V. Mamishev, Massachusetts Institute of Technology, "Measurement of Stratified Distributions of Dielectric Properties and Dependent Physical Variables" (Symposium EE)

Jeffery B. Maxson, University of WisconsinMadison, "Comparative Studies of the Surface of GaN (0001) Thin Films with LEEM" (Symposium D)
Robert C. Mucic, Northwestern University, "Functional DNA/Nanoparticle-Based Materials" (Symposium FF)

Michael Natusch, University of Cambridge "Local Electronic Structure of Defects in GaN from Spatially Resolved Electron Energy-Loss Spectroscopy (EELS)" (Symposium D)

Ainissa G. Ramirez, Stanford University, "Influence of Annealing on the Microstructure of Amorphous Carbon Thin Films for Magnetic Hard Disks" (Symposium AA)

Rajesh A. Rao, Duke University, "Effect of Substrate Miscut and Lattice Mismatch on Grown Mechanisms of Epitaxial Metallic Oxide $\mathrm{SrRuO}_{3}$ Thin Films" and "Effect of Domain Structure on the Magnetoresistance of Epitaxial Thin Films of Ferromagnetic Metallic Oxide $\mathrm{SrRuO}_{3}$ " (Symposia $A$ and $V$ )

Lars Rebohle, Forschungszentrum Rossendorf, "Strong Blue and Violet Light Emission from Silicon and Germanium Implanted Silicon Dioxide" (Symposium $\mathrm{H}$ )

Serge Santos, Swiss Federal Institute of Technology, "A Novel Parallel-Rotation Algorithm for Atomistic Monte Carlo Simulation of Polymer Melts and Glasses" (Symposium P)

Michael C. Wanke, University of CaliforniaSanta Barbara, "Laser CVD Rapid Processing of Ceramic Photonic Band-Gap Microstructures" (Symposium W)

Andre Wong, University of British Columbia "Stability of Magnesium Implanted $\mathrm{YBa}_{2} \mathrm{Cu}_{3} \mathrm{O}_{7}$ Thin Films" (Symposium T)

Ke Yang, University of Massachusetts, "Three Dimensional Quantum Confinement in Gallium Nitride Nanoparticles" and "Characterizing the NLO Chromophore Orientation of Polymeric Film by Electroabsorption Spectroscopy" (Symposia C and J)

Stefano Zapperi, Boston University, "Driven Dynamics of a Ferromagnetic Domain Wall: A Theory for the Barkhausen Effect" (Symposium B) 